\title{
Morphine- and buprenorphine-induced analgesia and antihyperalgesia in a human inflammatory pain model: a double-blind, randomized, placebo-controlled, five-arm crossover study
}

\author{
This article was published in the following Dove Press journal: \\ Journal of Pain Research \\ 8 January 2013 \\ Number of times this article has been viewed
}

\author{
Pernille Ravn' \\ Erik L Secher ${ }^{2}$ \\ Ulrik Skram ${ }^{3}$ \\ Trine Therkildsen' \\ Lona L Christrup' \\ Mads U Werner ${ }^{4}$ \\ 'Department of Drug Design \\ and Pharmacology, University \\ of Copenhagen, ${ }^{2}$ Department of \\ Anesthesiology, Juliane Marie Center, \\ Rigshospitalet, Copenhagen University \\ Hospitals, ${ }^{3}$ Department of Intensive \\ Care, Gentofte Hospital, Copenhagen \\ University Hospitals, ${ }^{4}$ Multidisciplinary \\ Pain Center, Neuroscience Center, \\ Rigshospitalet, Copenhagen University \\ Hospitals, Copenhagen, Denmark
}

Purpose: Opioid therapy is associated with the development of tolerance and paradoxically increased sensitivity to pain. It has been suggested that buprenorphine is associated with a higher antihyperalgesia/analgesia ratio than $\mu$-opioid receptor agonists. The primary outcome of this study was therefore to investigate relative differences in antihyperalgesia and analgesia effects between morphine and buprenorphine in an inflammatory pain model in volunteers. The secondary outcome was to examine the relationship between pain sensitivity and opioid-induced effects on analgesia, antihyperalgesia, and descending pain modulation.

Subjects and methods: Twenty-eight healthy subjects were included. The study was a doubleblind, randomized, placebo-controlled, five-arm crossover study with a multimodal (electrical, mechanical, and thermal stimuli) testing technique. After baseline assessments, intravenous infusions of morphine $(10 / 20 \mathrm{mg})$, buprenorphine $(0.3 / 0.6 \mathrm{mg})$, or placebo (normal saline) were administered over a 210 -minute period, during which a cold pressor test, heat injury $\left(47^{\circ} \mathrm{C}\right.$, 7 minutes, $12.5 \mathrm{~cm}^{2}$ ), and the first postburn assessment were done. After completion of the drug infusions, two additional postburn assessments were done. The subjects were monitored during each 8-hour session by an anesthesiologist.

Results: For nearly all tested variables, significant dose-dependent analgesic effects were demonstrated. The median antihyperalgesia/analgesia ratio (secondary hyperalgesia/heat injury relative to placebo) for low-dose morphine was 0.01 (interquartile range: $-6.2 ; 9.9), 0.00(-2.4$; $2.1)$ for high-dose morphine, $0.03(-1.8 ; 2.1)$ for low-dose buprenorphine, and $0.00(-3.2$; 1.1) for high-dose buprenorphine $(P>0.466)$. There were no significant differences in opioid responses between high and low pain-sensitive subjects $(P>0.286)$. High-dose buprenorphine, compared to placebo, was associated with a significantly enhanced action of the descending inhibitory pain control system $(P=0.004)$.

Conclusion: The present study, using multimodal testing technique, could not demonstrate any significant differences between morphine and buprenorphine in the profiles of antihyperalgesia and analgesia. Only high-dose buprenorphine was associated with a significant effect on the descending inhibitory pain control system.

Keywords: analgesia, antihyperalgesia, experimental pain, opioid, pain sensitivity, randomized trial

\section{Introduction}

Opioids are generally considered cornerstones in management of high intensity acute and chronic pain. The opioid-mediated pain reduction is mainly caused by activation of opioid-receptors in the central nervous system, at spinal and supraspinal levels.
Correspondence: Pernille Ravn

Department of Drug Design and

Pharmacology, Copenhagen University, Universitetsparken 2, 2100 Copenhagen, Denmark

Tel +45 23456283

Fax +4535336050

Email ravn@farma.ku.dk 
Although peripherally mediated suppression of sensitized nociceptors by opioids has been reported, the general absence of antihyperalgesic effects in clinical studies suggests that opioids generally have only a minor effect in preventing central sensitization of the pain pathways. ${ }^{1}$ Furthermore, opioid therapy is associated with a development of tolerance and a paradoxically increased sensitivity to pain, ie, opioid-induced hyperalgesia. ${ }^{2,3}$ This is obviously of clinical concern since opioid therapy per se may aggravate pain and thus endanger adequate pain control., ${ }^{2,4}$ Different mechanisms have been proposed for opioid-induced hyperalgesia and opioid-induced analgesia. In a human experimental electrical pain model, buprenorphine - a partial $\mu$-opioid receptor (MOR) agonist and $\kappa$-opioid receptor (KOR) antagonist - seems to be associated with a higher antihyperalgesia/analgesia ratio than conventional MOR agonists morphine and fentanyl. ${ }^{5,6}$ If this also holds true for an inflammatory stimulus associated with primary and secondary hyperalgesia (2HA), the observations may implicate potential opioid receptor-specific effects on analgesia and antihyperalgesia in a clinical setting.

Furthermore, large variations in pain sensitivity and analgesic response profiles have been demonstrated in experimental and clinical research. ${ }^{7}$ A number of studies have shown that sensitivity to suprathreshold heat and pressure pain consistently predicts postoperative pain outcomes and susceptibility to chronic pain disorders. ${ }^{8-11}$ The descending conditioned pain modulation (CPM) system may be an important factor regulating pain sensitivity and the propensity for development of chronic pain. ${ }^{12,13}$ Recent human experimental data suggest that both fentanyl and buprenorphine increase the effect of descending pain inhibition using CPM. ${ }^{12}$ A better insight into the interaction between pain sensitivity and opioid response profile may lead to an increased understanding of clinical pain and its management.

The primary outcome of the study was to investigate relative differences in effects on antihyperalgesia and analgesia between morphine and buprenorphine in a validated, clinically relevant, inflammatory injury model. ${ }^{14-16}$ The secondary outcome was to examine the relationship between pain sensitivity and opioid-induced effects on analgesia, antihyperalgesia, and descending pain modulation.

\section{Subjects and methods Subjects}

The protocol was approved by the Regional Ethics Committee (H-2-2010-115), Danish Medicines Agency, Danish Data Protection Agency, and ClinicalTrials.gov (NCT01296334). Healthy subjects were recruited from a prior study; ${ }^{17}$ the volunteers with the highest and lowest pain responses (based on their visual analog scale [VAS] scores during the heat injury) were asked to participate in the present study. Inclusion criterion was 20-40 years of age. Exclusion criteria were insufficient proficiency in Danish, participation in other clinical trials in the last 4 weeks prior to the present study, skin lesions on the lower leg, intake of any medication 48 hours prior to the investigation, intake of analgesics 7 days prior to the investigation (except paracetamol), allergy to morphine, buprenorphine, hydrocortisone, ondansetron, or dehydrobenzperidol, current or former drug abuse, smoking, body mass index $>28$, and, in females, pregnancy, planning of pregnancy, or no use of contraception. Following verbal and written information, all subjects provided written informed consent before inclusion. All subjects had a routine medical examination by a physician prior to inclusion. Subjects received a compensation of $€ 675$, equivalent to USD890, for the five 8-hour study sessions.

\section{Study design}

The study was a double-blind, randomized, placebocontrolled, five-arm crossover study. Each study day was identical with only the study drugs differing between the five sessions (Figure 1).

\section{Study drugs}

Buprenorphine $\left(0.3 \mathrm{mg} / \mathrm{mL}\right.$; Temgesic ${ }^{\circledR}$; Reckitt Benckiser plc, Slough, United Kingdom) and morphine $(20 \mathrm{mg} / \mathrm{mL}$; morfin SAD) was mixed with and administered in $480 \mathrm{~mL}$ of $0.9 \%$ sodium chloride. Buprenorphine ( 0.3 and $0.6 \mathrm{mg})$, morphine (10 $\mathrm{mg}$ and $20 \mathrm{mg}$ ), and placebo (0.9\% sodium chloride) were administered as intravenous infusions over a 210-minute period. The target-controlled infusion regimens were chosen in order to obtain steady-state concentrations (until 1 hour postburn), and simulations were performed with pharmacokinetic calculation software (Berkeley Madonna version 8.3.18; University of California - Berkeley, Berkeley, CA), using data from Yassen et al and Mazoit et al. ${ }^{18,19}$ The dose was administered according to the following infusion regimen: 0-15 minutes, one-quarter of the dose was infused; 15-210 minutes, the remaining three-quarters of the dose was infused. The doses were chosen as an attempt to minimize potential adverse events, especially nausea and vomiting, but at the same time reach a significant difference between the high and low doses. Furthermore, to reduce the risk of adverse events, antiemetics (25 mg hydrocortisone succinate [Solu-Cortef ${ }^{\circledR}$; Pfizer, Inc, New York, NY] and 2 mg 


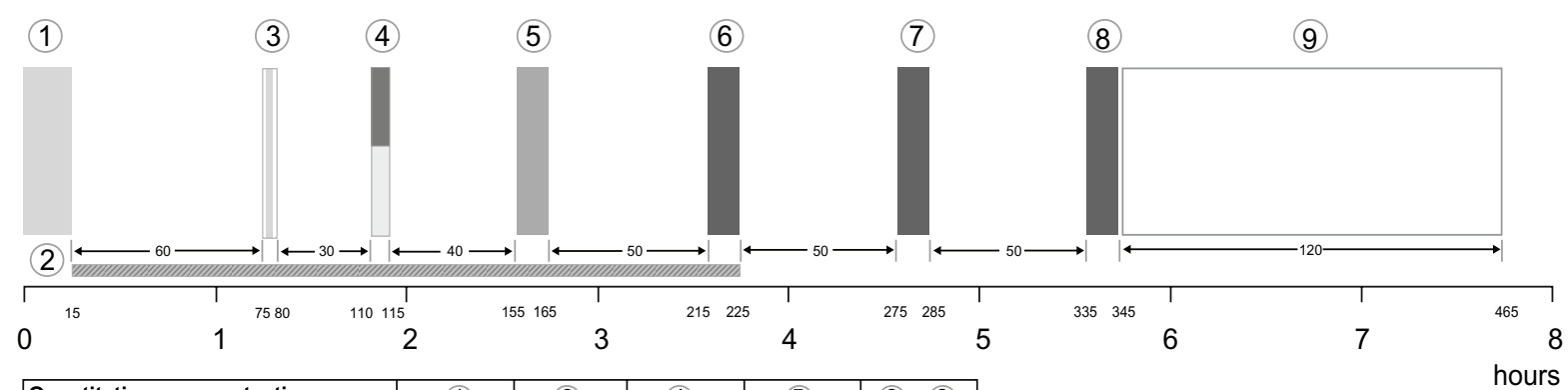

\begin{tabular}{|l|c|c|c|c|c|}
\hline Quantitative sensory testing & (1) & (3) & 4 & 5 & 6 - 8 \\
\hline Secondary hyperalgesia area & $\mathbf{x}$ & & & & $\mathbf{x}$ \\
\hline Thermal thresholds (WDT,CDT,HPT) & $\mathbf{x}$ & & & & $\mathbf{x}$ \\
\hline Electrical thresholds (EDT,EPT,EPTo) & $\mathbf{x}$ & & & & $\mathbf{x}$ \\
\hline Cold pressor test & & $\mathbf{x}$ & & & \\
\hline Pressure algometry & & $\mathbf{x}$ & & & \\
\hline Conditioned pain modulation efficiency & & & $\mathbf{x}$ & & \\
\hline Heat injury & & & & $\mathbf{x}$ & \\
\hline
\end{tabular}
(1) Baseline assessments (15 min)
(5) Heat injury (10 min)
(2) Drug infusion (210 min)
(6) - (8) Hourly post-heat injury assessments (10 min)
(3) Cold pressor test (5 min)
(9) Recovery phase (120 min)
(4) Conditioned pain modulation efficiency (5 $\mathrm{min})$

Figure I Study algorithm (the order of the tests in the baseline assessments are as listed in the table).

Abbreviations: CDT, cool detection threshold; EDT, electrical detection threshold; EPT, electrical pain threshold; EPTo, electrical pain tolerance; HPT, heat pain threshold; WDT, warmth detection threshold.

ondansetron [Zofran ${ }^{\circledR}$; GlaxoSmithKline plc, London, United Kingdom]) were administered prior to baseline assessments. ${ }^{20}$ Isotonic glucose $(1 \mathrm{~L})$ was administered (as an intravenous infusion during the 6-hour session) to attenuate the discomfort of fasting as the subjects were instructed not to eat and drink 8 hours and 2 hours, respectively, prior to study drug administration.

The randomization, blinding, and packaging of the drugs were performed by Herning Hospital Pharmacy (Herning, Denmark) using the second generator at randomization. com. The second generator creates random permutations of treatments for situations where subjects receive all of the treatments in random order. The packaging was identical for all five study drugs and the drug infusions were prepared 1-12 hours before use by pharmaceutical trained staff not involved in other parts of the study.

\section{Monitoring and surveillance}

All volunteers had a routine medical examination including an electrocardiogram taken before the first drug infusion. Noninvasive arterial blood pressure, heart rate, respiratory rate, and oxygen saturation were monitored and registered during the entire sessions. A registered nurse in anesthesia and an anesthesiologist were present during the full-length of the sessions, and the latter was responsible for the discharge of the subjects at the end of the study.

\section{Psychological tests}

At the first study session the volunteers completed the Hospital and Anxiety Depression Scale (HADS), Pain Catastrophizing Scale (PCS), and Psychological Vulnerability Scale. ${ }^{21-24}$ HADS is a 14-item questionnaire used to evaluate the subjects' level of anxiety and depression. The subjects can rate between zero and 21, with a score of eleven as the cutoff point for anxiety or depression. ${ }^{25}$ PCS is a 14-item questionnaire used to assess the subjects' rumination, magnification, and helplessness. The subjects can rate between zero and 52, with a total PCS score of 30 representing a clinically relevant level of catastrophizing. ${ }^{22}$ The Psychological Vulnerability Scale is a six-item questionnaire used to determine the subjects' psychological vulnerability. The subjects can rate between zero and twelve, with a score of three as the cutoff point. ${ }^{23,26}$

\section{Psychomotor performance}

The finger tapping test (FTT) was used at the beginning and at the end of each session to test the subjects' psychomotor performance. ${ }^{27} \mathrm{FTT}$ is a simple reaction time measurement, where the subjects press a spring lever with their dominant index finger as many times as possible in 10 seconds. This is repeated five times and the average scores from the initial (predrug) and final (postdrug) tests from each session were compared as a control of the normalization of the subjects' psychomotor performance. 


\section{Perception of drug effect/drug liking}

At the end of each session, the subjects rated the drug effect and drug liking of the given treatment. ${ }^{28}$ The subjective drug effect was evaluated on a scale from 0 to $5(0=$ no effect, $5=$ maximum effect $)$ and the liking was evaluated on a scale from 0 to $10(0=$ feeling extreme discomfort, $5=$ neither discomfort nor comfort, $10=$ feeling extreme comfort). Subjects with a drug effect score of at least 4 and a drug liking score of at least 8 were excluded from continuing on in the trial. Moreover, a drug liking score of at least 9 , regardless of the drug effect score, would exclude a subject from the remaining part of the study.

The drug effect scores were reduced by five in order to interrelate the two scales so that zero equaled no effect and no like/dislike (negative $5=$ extreme discomfort, $5=$ extreme comfort).

\section{Retrospective identification of placebo day}

At the end of the fifth, and final, session, the subjects were asked to identify the study day on which they believed they had received the placebo.

\section{Psychophysiological pain tests Environment and testing paradigm}

All tests were performed in a well-lit room $\left(21^{\circ} \mathrm{C}-24^{\circ} \mathrm{C}\right.$, $24 \%-45 \%$ relative humidity) with the subjects comfortably relaxed in the supine position. The subjects were blinded to the test results during the study.

Assessments were made on five study sessions, each of 8 hours duration and separated by a minimum of 2 weeks. Two investigators (PR, TT) made the assessments. The study algorithm is illustrated in Figure 1.

\section{Testing areas}

The testing area for thermal thresholds and 2HA was the upper medial part of the nondominant lower leg. ${ }^{16}$ The subjects were instructed to use a hair trimmer in the area 2 days before the study days in order to avoid interference from the tactile stimulation of hairs. The three other testing areas were the nondominant thumb and index finger for electrical thresholds, the nondominant index finger for pressure thresholds, and the dominant hand for CPM and cold pressor test (CPT).

\section{Electrical stimulation}

Transcutaneous electrical stimuli were applied by a computerized, constant current stimulator (PainMatcher ${ }^{\circledR}$;
Cefar Medical AB, Lund, Sweden). ${ }^{29}$ The stimulator delivers square wave impulses with a frequency of $10 \mathrm{~Hz}$ and an amplitude of $15 \mathrm{~mA}$. The stimulation intensity is automatically modulated by increasing the pulse width (in 4 microsecond increments) from 4 microseconds to a maximum of 396 microseconds. The subject pinches the two opposing rubber electrodes between the nondominant thumb and index finger. By holding a steady grip on the electrodes, an incremental increase in the electrical energy is delivered. When releasing the pinch grip a value between one and 100, reflecting the energy delivered, is registered. The electrical detection threshold (EDT), electrical pain threshold (EPT), and electrical pain tolerance (EPTo) were assessed.

\section{Mechanical stimulation}

Electronic pinprick algometry

The pinprick pain threshold was measured by an electronic pinprick algometer (Electronic von Frey; Somedic AB, Horby, Sweden). ${ }^{30}$ The contact diameter of the probe was $0.2 \mathrm{~mm}$ (area $0.031 \mathrm{~mm}^{2}$ ). At each start-up, the algometer was calibrated against gravity $(0 \mathrm{~g})$ and a calibrated weight $(20 \mathrm{~g})$. In order to not exceed a range of skin pressures that could inflict tissue damage, the electronic pinprick algometer has a cutoff force value of $4.41 \mathrm{~N}$. The subjects were told to indicate the pain threshold on an electronic visual analog scale (VAS) without indicator markings (horizontal $10 \mathrm{~cm}$ line anchored by $0=$ no pain and $10=$ maximum pain imaginable). The pinprick pain threshold corresponded to a minimum detectable movement of the ruler (electronic VAS $=0.02$ ).

\section{Monofilaments}

The area of 2HA in normal skin surrounding the area of the heat injury was determined with a nylon filament (nominal value mean \pm standard deviation: \#18 [0.89 $\pm 0.05 \mathrm{~N}]$; Stoelting Co, Wood Dale, IL). ${ }^{31}$ The border was determined by stimulating in eight symmetric lines, each separated by an angle of 45 degrees converging towards the center of the heat injury. The subjects, who had their eyes closed during the assessments, reported the occurrence of a definite uncomfortable change in sensation to a burning or stinging sensation. The corners of the octagon were marked on the skin and transferred to a transparent sheath. The $2 \mathrm{HA}$ areas were calculated (total area minus area of the thermode) using a computerbased vector algorithm (Canvas 12.0; ACD Systems International, Victoria, Canada). 


\section{Thermal stimulation}

Warmth detection threshold (WDT), cool detection threshold (CDT), heat pain threshold (HPT)

Thermal stimuli were delivered through a computerized system (MSA Thermotest ${ }^{\mathbb{1}}$; Somedic AB) using a Peltier thermode with a contact area of $5.0 \times 2.5 \mathrm{~cm}^{2} .{ }^{16}$ Thermal neutrality was defined as $32^{\circ} \mathrm{C}$, and cutoff values for heat and cold stimuli were $50^{\circ} \mathrm{C}$ and $10^{\circ} \mathrm{C}$, respectively. The ramp rates were $\pm 2^{\circ} \mathrm{C} /$ second. The subjects were told to activate a button immediately at sensation of a change in temperature (WDT, CDT) and when the heat was perceived as pain (HPT). After activation of the button, the thermode returned to $32^{\circ} \mathrm{C}$. At each study session, each test was performed in triplicate with random intervals of 2-6 seconds between the three runs, and the median value was used.

\section{Heat injury}

A first-degree heat injury was induced by the thermode $\left(47^{\circ} \mathrm{C}, 420\right.$ seconds) applied to the lower nondominant leg. The injury is associated with development of erythema and tenderness. The subject rated the pain on a VAS $(0=$ no pain, $10=$ maximum pain imaginable) immediately when $47^{\circ} \mathrm{C}$ had been reached, after 30 seconds, and thereafter every 60 seconds. The cumulated pain intensity during the heat injury (PHI) was calculated as follows:

$$
\begin{aligned}
\mathrm{PHI}= & \left(\mathrm{VAS}_{0 \mathrm{~s}}+\mathrm{VAS}_{30 \mathrm{~s}}\right) \times 0.5+\mathrm{VAS}_{60 \mathrm{~s}} \\
& +\mathrm{VAS}_{120 \mathrm{~s}} \ldots+\mathrm{VAS}_{420 \mathrm{~s}}
\end{aligned}
$$

\section{Antihyperalgesia/analgesia ratio}

The ratio of antihyperalgesia/analgesia $(\Delta 2 \mathrm{HA} / \Delta \mathrm{PHI}$ and $\Delta 2 \mathrm{HA} / \triangle \mathrm{EPTo}$ ) was calculated using the mean $1-3$ hour postburn values of the $2 \mathrm{HA}$ areas divided by the placebocorrected PHI scores or the mean values of the placebocorrected EPTo, respectively, with equations two and three leading to equation four:

$$
\begin{gathered}
\Delta 2 H A(\%)=100 \times \frac{2 H A_{\text {placebo }}^{\text {mean }}-2 H A_{\text {opioid }}^{\text {mean }}}{2 H A_{\text {placebo }}^{\text {mean }}} \\
\Delta P H I(\%)=100 \times \frac{P H I_{\text {placebo }}^{\text {mean }}-P H I_{\text {opioid }}^{\text {mean }}}{P H I_{\text {placebo }}^{\text {mean }}} \\
\frac{\Delta 2 H A}{\Delta P H I}=\frac{P H I_{\text {placebo }}^{\text {mean }}}{2 H A_{\text {placebo }}^{\text {man }}} \times \frac{2 H A_{\text {placebo }}^{\text {mean }}-2 H A_{\text {opioid }}^{\text {mean }}}{P H I_{\text {placeebo }}^{\text {man }}-P H I_{\text {opioid }}^{\text {man }}}
\end{gathered}
$$

\section{CPT and pressure algometry}

A recirculating $0.9 \%$ saline-based chiller (model 11371P; VWR International, Radnor, PA) with a bath volume of
$13 \mathrm{~L}$ was used for the CPT. The temperature was maintained at $0.3^{\circ} \mathrm{C}-0.5^{\circ} \mathrm{C}$. An electronic algometer with a $1 \mathrm{~cm}^{2}$ neoprene-coated tip (Somedic AB; rate: $30-40 \mathrm{mN}$ / second) was applied on the dorsum of the distal phalanx of the dominant index finger (deep sensitivity pain). The subject was told to activate a button terminating the stimulus when the maximum tolerable pressure level was reached (PTo1). The subject then submerged the nondominant hand in the bath maintaining the water level at $1-2 \mathrm{~cm}$ above the wrist, spreading the fingers, and allowing water freely to circulate around the hand. The time to pain registration (ie, CPT pain threshold [CPP]) and time to pain tolerance (ie, CPT pain tolerance [CPTo]) were registered. Immediately after withdrawal of the hand from the bath, a second pressure algometry test at the dominant index finger was made (PTo2). The difference in pressure pain thresholds was calculated as $\Delta \mathrm{PTo}=\mathrm{PTo} 2-\mathrm{PTo} 1$.

\section{CPM efficiency ${ }^{\mathrm{a}}$}

The CPM efficiency test has been used in clinical studies to predict the development of chronic postoperative pain. ${ }^{32-34}$ In the CPM efficiency paradigm, repeated short heat stimuli $\left(47^{\circ} \mathrm{C}, 4\right.$ seconds; Figure 3$)$ were applied to the nondominant lower leg (nonglabrous skin) in relation to the submersion of the nondominant hand in the CPT water bath $\left(0.3^{\circ} \mathrm{C}-0.5^{\circ} \mathrm{C}, 30\right.$ seconds $) .{ }^{32}$ During the heat stimuli, the subjects rated their maximal pain (CPM1 - CPM4; Figure 3 ) on the VAS. The subjects were instructed only to evaluate the pain from the heat stimulation. CPM efficiency was calculated as:

$$
\triangle C P M(\%)=100 \times\left(1-\frac{C P M 2+C P M 3+C P M 4}{3 \times C P M 1}\right)
$$

\section{Pain sensitivity Definition of pain sensitivity}

Pain sensitivity has been defined as the proneness to react to standardized experimental or pathological stimuli. Pain ratings of seemingly identical noxious stimuli may range from "no pain" to "excruciating pain". ${ }^{35}$ The volunteers in the present study were categorized as high or low painsensitive subjects based on their PHI from a preceding study $(\mathrm{n}=100) \cdot{ }^{17}$ The tertiles with the highest and lowest pain scores were recruited, resulting in 64 intention-to-treat subjects.

${ }^{\mathrm{a} C a l l e d ~ d i f f u s e ~ n o x i o u s ~ i n h i b i t o r y ~ c o n t r o l ~(D N I C) ~ e f f i c i e n c y ~ i n ~ e x p e r i m e n t a l ~}$ animal studies. 


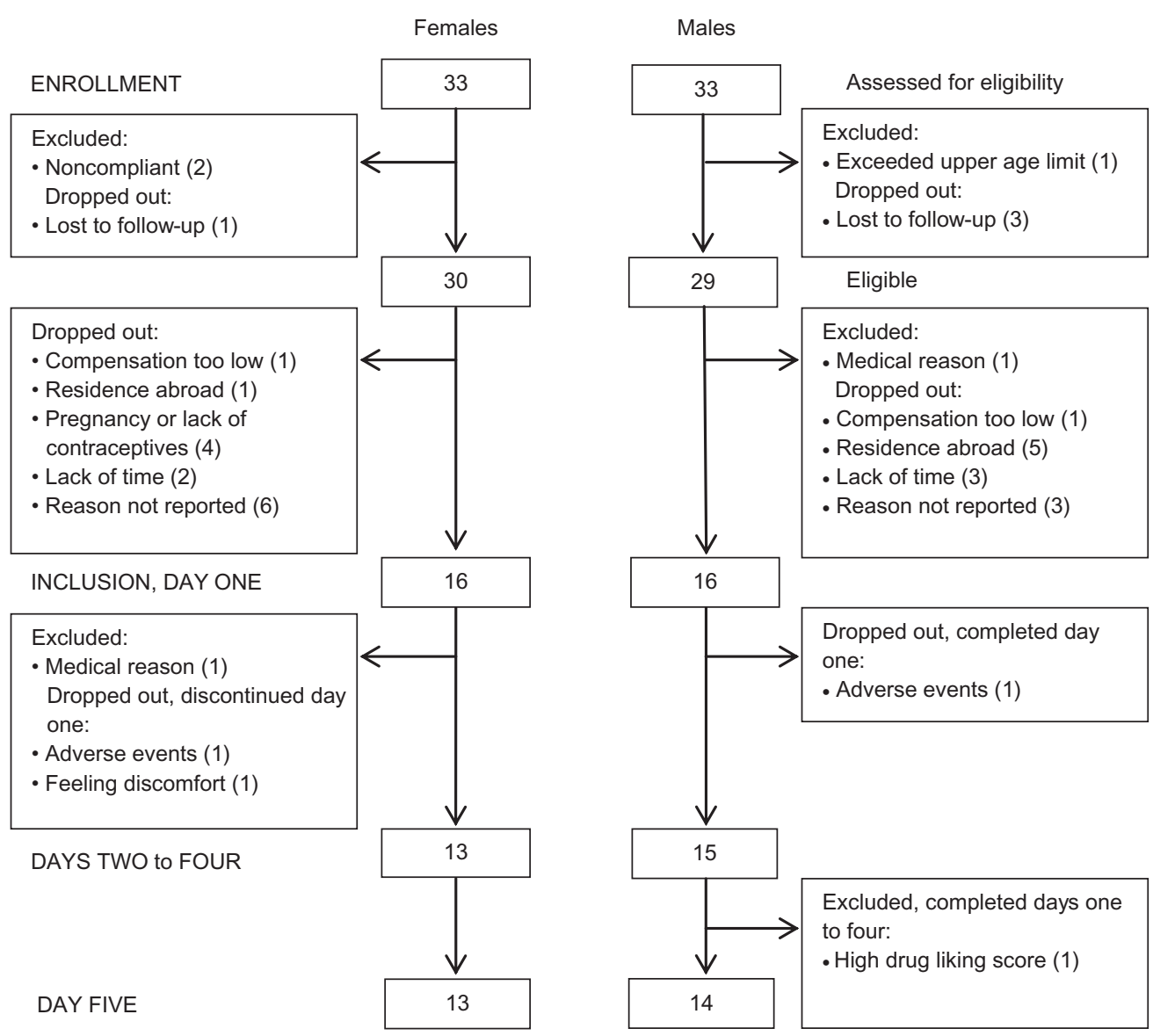

Figure 2 Participant flow-diagram.

Notes: Participant flow-diagram of the study illustrating patient enrollment, inclusion, the two study days and analysis. The intention-to-treat (ITT) and per-protocol (PP) groups were 33/33 (females/males) and 13/14, respectively.

\section{Statistical analyses}

The power analysis was based on the estimates that the antihyperalgesia/analgesia $(\Delta 2 \mathrm{HA} / \Delta \mathrm{PHI})$ ratio was $2.6,{ }^{6}$ the intraindividual standard deviation was 1.5 , and the minimal detectable difference was 1.8. On the assumptions that the power was set to 0.9 and the significance level to 0.01 , a minimum of 25 subjects was needed. The power analysis was based on the lower buprenorphine dose $(0.3 \mathrm{mg})$.

For all the postburn assessments (1-3 hours postburn), the analyses used mean values and the data were baseline (preburn) corrected. The data were tested for pain sensitivity-dependent differences on placebo as well as the opioid treatments corrected for placebo. In the case of floor or ceiling effect, nonparametric analysis was used with the maximum obtainable value plus one or the minimum obtainable value changed from 0 to 0.01 .

All data were tested for normal distribution and parametric analyses were performed where possible. In nonnormal distributions, transformations were tried. In nonsuccessful transformations, nonparametric analyses were performed. Analyses of the differences between the treatments and pain sensitivity were done by repeated measures one-way analysis of variance (ANOVA). In cases of significance $(P<0.05)$, paired $t$-tests or Wilcoxon signed-rank tests (based on the distribution) were performed. The psychological variables were analyzed with Fischer's exact test. All statistics were performed with PASW version 18.0 (IBM Corporation, Armonk, NY).

There were five treatment groups for each outcome, resulting in ten pairwise comparisons. In order to reduce the likelihood of a type I error caused by multiple comparisons, the significance level was set at $P<0.005$ for all analyses, based on a standard Bonferroni correction. Continuous data are presented as mean \pm standard error of the mean unless otherwise stated.

\section{Results Subjects}

The intention-to-treat and per-protocol groups were 33/33 (males/females) and 14/13, respectively (Figure 2).

One subject only completed four treatments due to exclusion for the remaining part of study (low-dose 


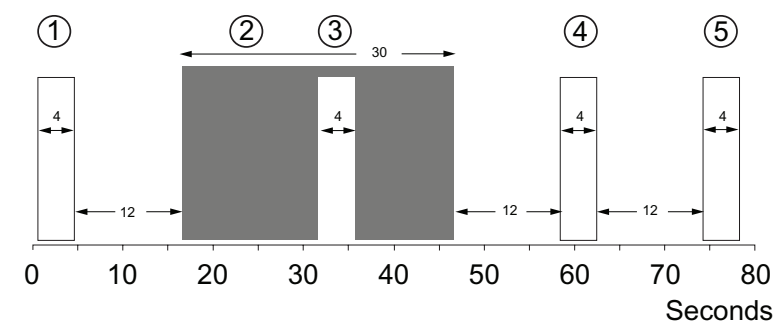

Figure 3 CPM-efficiency.

Notes: The conditioned pain modulation (CPM) efficiency with repeated phasic heat stimuli $\left(47^{\circ} \mathrm{C}, 4 \mathrm{~s}[1,3,4,5]\right)$ in relation to submersion of the non-dominant hand (2) in the cold pressor test (CPT $\left.\left[0.3^{\circ} \mathrm{C}-0.5^{\circ} \mathrm{C}, 30 \mathrm{~s}\right]\right)$. During the phasic heat stimuli, the subjects rated their maximal pain on a visual analog scale (VAS [0-10]).

morphine), caused by high rating scores on the drug effect and drug liking scales. This subject was included in all analyses possible. One subject withdrew after one session due to adverse events and two subjects withdrew before completion - one subject due to feeling uncomfortable before drug infusion and one subject due to adverse events (none of these three subjects were included in the analyses).

The high and low pain-sensitive subjects in the perprotocol groups were evenly distributed in the male group ( $n=7$ in both groups; the male completing only four out of five sessions had low sensitivity) and in the female group ( $n=7$ and $n=6$, respectively).

A significant gender difference was seen in regard to height, weight, and body surface area $(P<0.0001$; Table 1$) .{ }^{36}$ A trend in gender-related difference in age distribution was seen $(P=0.012)$. No significant gender difference was seen in body mass index $(P=0.328)$.

All subjects were examined by two female investigators (PR: 61\%; TT: 39\%).

\section{Psychological variables}

None of the subjects had HADS subscores indicating depression symptoms. One male subject had a HADS subscore demonstrating anxiety $($ score $=14)$ and three subjects (one male, two females) had Psychological Vulnerability Scale scores indicating psychological vulnerability. Eight subjects (five males and three females) had Pain Catastrophizing Scale (PCS) scores indicating catastrophizing thoughts. The PCS scores for males and females were 6.0 and 5.3 for rumination, 2.1 and 1.8 for magnification and 4.4 and 3.7 or helplessness, respectively.

No significant correlations between any of the psychometric variables and gender $(P>0.343)$ or sensitivity $(P>0.067)$ were observed.

\section{Psychomotor performance}

The subjects had a higher score on the FTT at the end of the sessions (postdrug) compared to the test performed at the beginning of the sessions (predrug), with an overall increase of 4.3 taps. No significant differences were seen between the five sessions on the predrug FTT $(P>0.063)$ or the postdrug FTT $(P>0.359)$.

\section{Drug effect/drug liking}

The subjective rating of the drug effect during the opioid treatments differed significantly from placebo $(P<0.0001$; Figure 4). Increased drug effect was observed for both doses of buprenorphine and high-dose morphine compared to lowdose morphine and for high-dose buprenorphine compared to high-dose morphine $(P<0.0001)$. The rating for drug liking demonstrated a lower score for high-dose buprenorphine compared to low-dose morphine $(P=0.004)$. None of the other opioid comparisons differed $(P>0.010)$, nor did any of the opioids compared to placebo $(P>0.016)$.

\section{Retrospective identification of the placebo day}

Twenty-three (85\%) subjects identified the correct study session as the placebo treatment. Four subjects (15\%) identified low-dose morphine as the placebo treatment.

\section{Psychophysiological pain tests}

Several tests contained floor or ceiling values and several subjects reached these cutoff values (Table 2).

\section{Baseline comparisons}

All the tests performed before drug infusion (baseline assessments; Figure 1) were analyzed for differences between

Table I Anthropometric data

\begin{tabular}{|c|c|c|c|c|c|}
\hline Gender & $\begin{array}{l}\text { Age } \\
\text { (years) }\end{array}$ & $\begin{array}{l}\text { Height } \\
(\mathrm{cm})\end{array}$ & $\begin{array}{l}\text { Weight } \\
\text { (kg) }\end{array}$ & $\begin{array}{l}\text { BMI } \\
\left(\mathrm{kg} / \mathrm{m}^{2}\right)\end{array}$ & $\begin{array}{l}\text { BSA } \\
\left(m^{2}\right)\end{array}$ \\
\hline Females $(n=13)$ & $23.2(2.0)$ & $168.3(6.2)$ & $64.7(7.4)$ & $22.9(2.6)$ & $1.74(0.12)$ \\
\hline Males $(n=15)$ & $26.7(4.3)$ & I 84.4 (7.5) & $81.0(9.4)$ & $23.8(2.2)$ & $2.03(0.15)$ \\
\hline Females and males & $25.1(3.8)$ & $176.9(10.6)$ & 73.4 (II.8) & $23.4(2.4)$ & $1.90(0.20)$ \\
\hline
\end{tabular}

Notes: Age (years), height $(\mathrm{cm})$, weight $(\mathrm{kg}), \mathrm{BMI}\left(\mathrm{kg} / \mathrm{m}^{2}\right)$ and BSA $\left(\mathrm{m}^{2}\right)^{36}$ for females, males and both genders combined (mean [SD]).

Abbreviations: BMI, Body Mass Index; BSA, Body Surface Area; SD, standard deviation. 


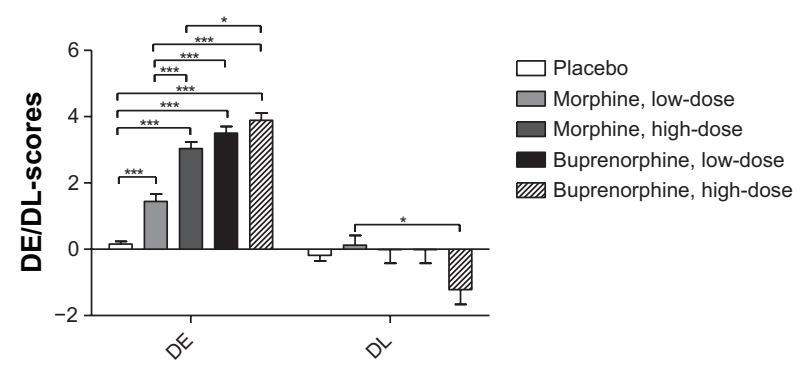

Figure 4 Drug effect and drug like.

Note: Drug effect and drug like scores for placebo, morphine and buprenorphine (low- and high-doses). $* P<0.005$, $* * P<0.001$, **** $P<0.0001$.

Abbreviations: $\mathrm{DE}$, drug effect; $\mathrm{DL}$, drug like.

the five study sessions and for potential pain sensitivity differences (low versus high pain-sensitive subjects). None of the baseline assessments before drug infusion differed significantly between the sessions (Table 3 ).

In baseline assessments of EPTo, significant differences in pain sensitivity were found for the sessions when highdose morphine, high-dose buprenorphine, and placebo were administered $(P<0.005$; Table 3$)$.

\section{Comparisons across treatments}

Electrical stimulation

The repeated measures ANOVA showed significant differences between the treatments for all three electrical tests:

Table 2 Tests affected by floor or ceiling values

\begin{tabular}{|c|c|c|c|c|c|c|}
\hline \multirow[t]{2}{*}{ Test } & \multirow[t]{2}{*}{ Cut-off } & \multirow[t]{2}{*}{ Placebo } & \multicolumn{2}{|c|}{ Morphine } & \multicolumn{2}{|c|}{ Buprenorphine } \\
\hline & & & Low & High & Low & High \\
\hline \multicolumn{7}{|l|}{ Ceiling } \\
\hline EPTo, preburn & 100 & I & I & 2 & 2 & 2 \\
\hline EPTo, PBI & Units & 1 & I & 4 & 7 & 8 \\
\hline EPTo, PB2 & & I & 3 & 6 & 6 & 8 \\
\hline EPTo, РB3 & & I & 3 & 6 & 5 & 8 \\
\hline HPT, preburn & $50^{\circ} \mathrm{C}$ & 4 & 4 & 5 & 6 & 3 \\
\hline HPT, PBI & & 5 & 5 & 5 & 8 & II \\
\hline HPT, PB2 & & 5 & 10 & 9 & 12 & 17 \\
\hline HPT, PB3 & & 6 & 10 & 8 & II & 12 \\
\hline CPP & $180 \mathrm{sec}$ & 0 & I & 2 & I & 3 \\
\hline CPTо & & 9 & 12 & 13 & 14 & 15 \\
\hline PTol & $1.600 \mathrm{~g}$ & I & 5 & 6 & 2 & 4 \\
\hline PTo2 & & 0 & 2 & 4 & 4 & 6 \\
\hline \multicolumn{7}{|l|}{ Floor } \\
\hline 2HA, PB I & $0 \mathrm{~cm}^{2}$ & 6 & 5 & 6 & 5 & 6 \\
\hline 2HA, PB 2 & & 6 & 5 & 5 & 7 & 6 \\
\hline $2 \mathrm{HA}, \mathrm{PB} 3$ & & 6 & 6 & 5 & 10 & 7 \\
\hline
\end{tabular}

Notes: Number of subjects for each assessment variable reaching floor or ceiling values divided on placebo, low- and high-dose morphine and low- and high-dose buprenorphine ( $n=28$ in all groups, except low dose morphine, $n=27)$.

Abbreviations: EPTo, electrical pain threshold; HPT, heat pain threshold; CPP, cold pressor test pain threshold; CPTo, cold pressor test pain tolerance; PTol, pressure pain tolerance (before CPT); PTo2, pressure pain tolerance (after CPT); $2 \mathrm{HA}$, secondary hyperalgesia area; $\mathrm{PBI}$, I hour postburn; PB2, 2 hours postburn; PB3, 3 hours postburn.
EDT, EPT, and EPTo $(P=0.001, P=0.001$, and $P=0.0001$, respectively).

No significant differences were seen in EDT when comparing opioids to placebo $(P>0.027)$ or when comparing opioids reciprocally $(P>0.016)$.

Analgesic effects in EPT and EPTo assessments were seen with both doses of buprenorphine and high-dose morphine when compared to placebo $(P<0.0001$ and $P<0.0001$, respectively), but not when comparing lowdose morphine with placebo $(P=0.454$ and $P=0.011$, respectively; Figure 5). Comparing the opioid treatments, a significant lower analgesic effect was seen in EPT for low-dose morphine compared to the two doses of buprenorphine and high-dose morphine $(P<0.005)$. EPTo was also significantly lower for low-dose morphine compared to the two doses of buprenorphine $(P<0.003)$.

\section{Thermal stimulation}

Differences between the treatments were seen in CDT and HPT $(P=0.0001)$, but not in WDT $(P=0.236)$.

\section{CDT}

Significantly decreased CDTs (numerically increased thresholds) were observed for both doses of buprenorphine and high-dose morphine compared to placebo $(P<0.0001)$, while significantly increased CDTs (numerically decreased thresholds) were seen for low-dose morphine compared to placebo $(P=0.0001)$ and low-dose morphine compared to the two doses of buprenorphine $(P<0.002$; Figure 6).

\section{HPT}

A significantly increased analgesic effect was found for highdose buprenorphine compared to placebo $(P=0.001)$. Highdose buprenorphine also showed a significantly increased analgesic effect when compared to both doses of morphine $(P<0.001$; Figure 6).

\section{Heat injury}

The repeated measures ANOVA revealed significant differences between the treatments in relation to PHI $(P=0.0001)$. A significant analgesic effect during the heat injury was demonstrated for both doses of buprenorphine and high-dose morphine compared to placebo $(P<0.003$; Figure 7$)$, but not for low-dose morphine compared to placebo $(P=0.022)$. The analgesic effect of high-dose buprenorphine was also significantly larger compared to the analgesic effect of lowdose morphine $(P=0.002)$. 
Table 3 Baseline comparisons

\begin{tabular}{|c|c|c|c|c|c|c|}
\hline Differences between & EDT & EPT & EPTo & WDT & CDT & HPT \\
\hline Sessions & $>0.363$ & $>0.187$ & $>0.065$ & $>0.057$ & $>0.132$ & $>0.041$ \\
\hline High and low pain sensitive subjects & $>0.009$ & $>0.310$ & $>0.005$ & $>0.114$ & $>0.333$ & $>0.248$ \\
\hline
\end{tabular}

Notes: Baseline comparison of the five baseline measurements (between sessions) and tests for pain sensitivity differences (between high- and low pain sensitive subjects). Lowest $P$-values from the 10 comparisons are reported.

Abbreviations: EDT, electrical detection threshold; EPT, electrical pain threshold; EPTo, electrical pain tolerance; WDT, warmth detection threshold; CDT, cold detection threshold; HPT, heat pain threshold.

\section{Pressure stimulation and CPT}

No significant differences were found between the first and second pressure stimulation test in any of the treatment groups $(P=0.708)$, but a trend in treatment differences were seen in PTo1 and PTo2 ( $P=0.008$ and $P=0.006$, respectively). The repeated measures ANOVA also showed significant differences in CPP and CPTo $(P=0.015$ and $P=0.0001)$.

Pressure pain tolerances (PTo1, PTo2) were significantly lower in the placebo group compared to high-dose buprenorphine and high-dose morphine $(P<0.005)$, and the difference in pressure pain thresholds was significantly lower for placebo compared to high-dose buprenorphine ( $P=0.003$; Figure 8$)$.

A significant increase in CPPs was seen with both doses of buprenorphine and high-dose morphine compared to placebo

A
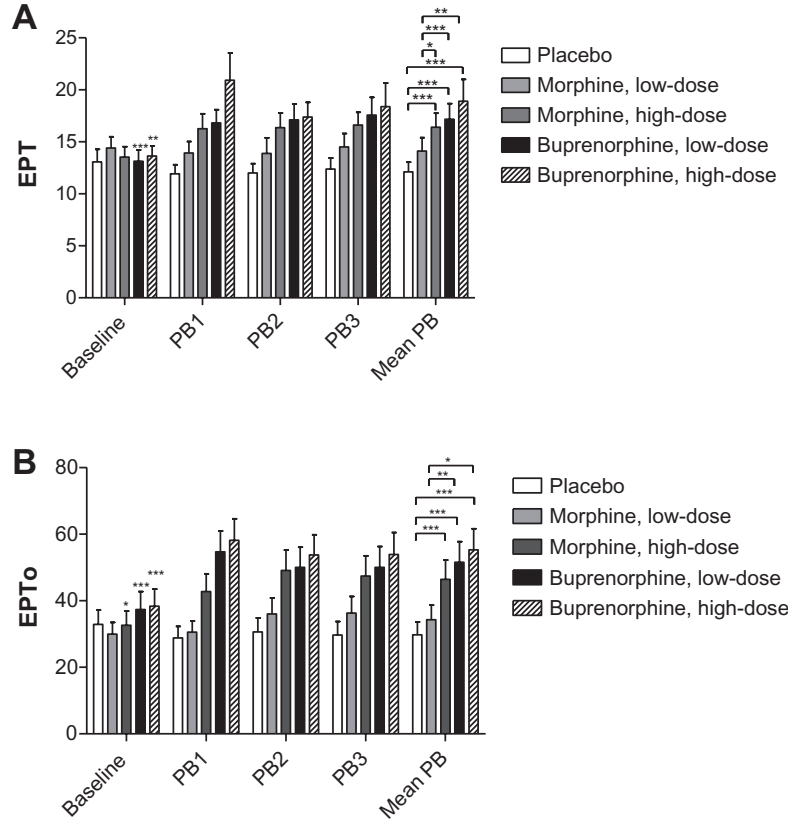

Figure 5 Electrical pain threshold and electrical pain tolerance.

Notes: Electrical pain threshold and electrical pain tolerance for baseline, postburn I-3 assessments and mean postburn assessments. The asterisks on baseline values indicates differences between baseline and its respective mean postburn value, while asterisks on mean postburn values indicate differences between the five sessions mean postburn assessments.

Abbreviations: EPT, Electrical pain threshold; EPTo, electrical pain tolerance; Mean PB, mean of PBI, PB2 and PB3; PBI, I hour postburn; PB2, 2 hours postburn; PB3, 3 hours postburn.
$(P<0.004$; Figure 8). All opioid treatments significantly increased CPTo compared to placebo $(P<0.001$; Figure 9$)$, but none of the opioid treatments differed significantly $(P>0.009)$.

\section{CPM efficiency}

The repeated measures ANOVA revealed significant differences in CPM efficiency $(P<0.001)$.

High-dose buprenorphine showed a significant analgesic effect compared to placebo ( $P=0.004$; Figure 10$)$, which was not seen when comparing the other three opioids to placebo $(P>0.012)$. No significant differences were found when comparing the opioid treatments reciprocally $(P>0.009)$.
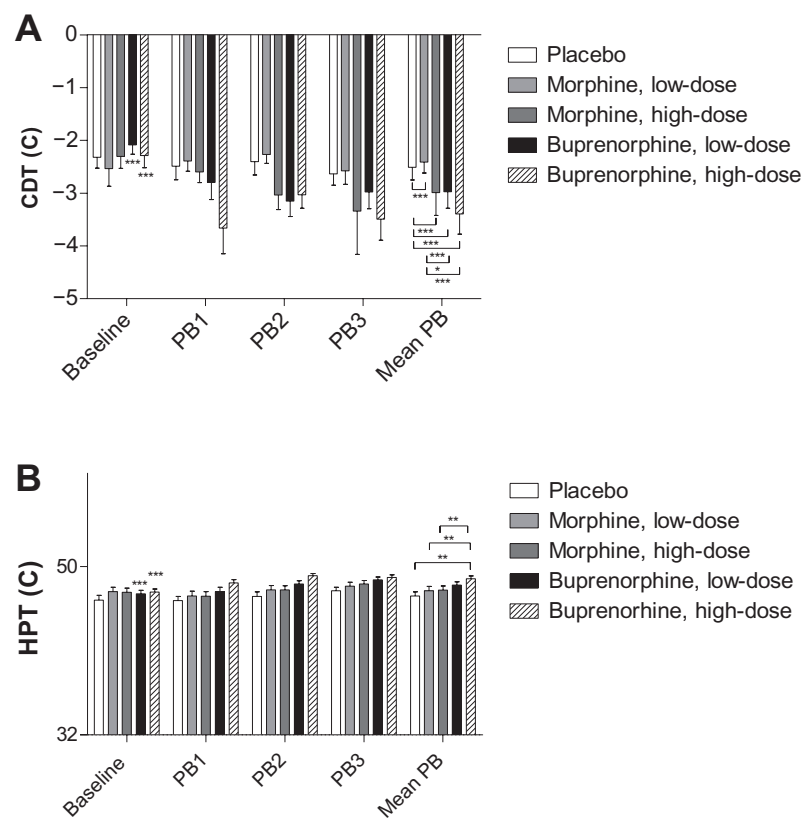

Figure $6 \mathrm{Cool}$ detection threshold and heat pain threshold.

Notes: Cool Detection Threshold (CDT) and Heat Pain Threshold (HPT) for baseline, postburn I-3 (PBI-3) and mean postburn (mean PB) assessments. The asterisks on baseline values indicate differences between baseline and its respective mean postburn value while asterisks on mean postburn values indicate differences between the five sessions mean postburn assessments.

Abbreviations: CDT, cool detection threshold; HPT, heat pain threshold; Mean PB, mean of PBI, PB2 and PB3; PBI, I hour postburn; PB2, 2 hours postburn; PB3, 3 hours postburn. 


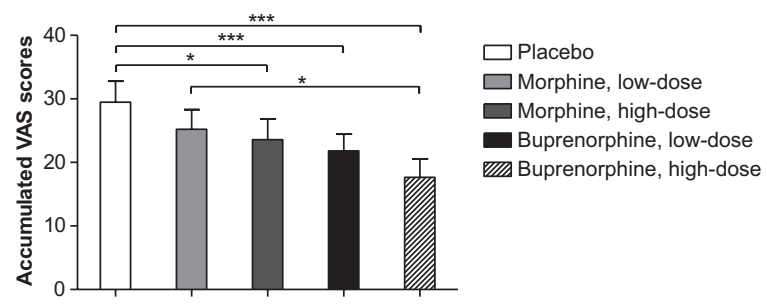

Figure 7 Accumulated visual analog scale scores during heat injury.

Notes: Accumulated VAS scores [0-10] during the heat injury. ${ }^{*} P<0.005$, $* * P<0.001$, $* * * P<0.0001$.

Abbreviation: VAS, visual analog scale.

\section{HA}

Repeated measures ANOVA did not demonstrate any significant differences in the areas of $2 \mathrm{HA}(P=0.773$; Figure 11$)$.

\section{Antihyperalgesic/analgesic effect}

No significant differences were seen when comparing the opioids in regard to $\Delta 2 \mathrm{HA} / \Delta \mathrm{PHI}(P>0.466)$. In regard to $\triangle 2 \mathrm{HA} / \triangle \mathrm{EPT}$, significant differences were only seen in low-dose morphine compared to the other active groups $(P<0.001)$. The antihyperalgesic/analgesic effect values relative to placebo and the ratios are presented in Figure 12.

\section{Pain sensitivity differences}

Only the heat injury at the placebo session showed significant pain sensitivity differences $(P=0.001)$.

\section{Adverse events}

Nausea, vomiting, itching, sedation, and arterial desaturation were the most frequent adverse events (Table 4). A significant increased number of adverse events were seen for both doses of buprenorphine and for high-dose morphine compared to placebo $(P<0.0001)$, while no significant difference between low-dose morphine and placebo was observed $(P=0.027)$. An increased number of adverse events were reported during treatment with high-dose buprenorphine compared with the other treatments $(P<0.003)$. There was no significant

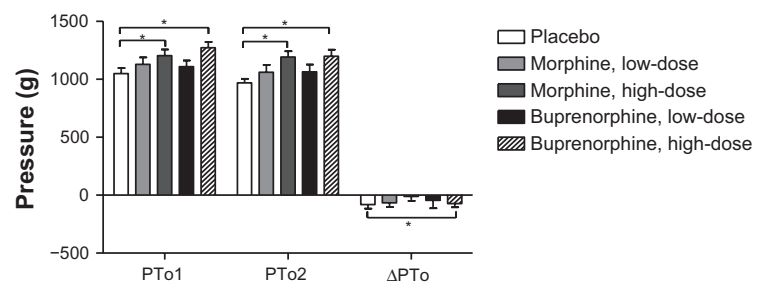

Figure 8 Pressure algometry.

Notes: Pressure pain tolerance before and after the cold pressor test, and delta pressure pain tolerance. $* P<0.005$, $* * P<0.001$, $* * * p<0.0001$.

Abbreviations: PTol, pressure pain tolerance before CPT; PTo2, pressure pain tolerance after CPT; $\triangle \mathrm{PTo}=\mathrm{PTo} 2-\mathrm{PTol}$.

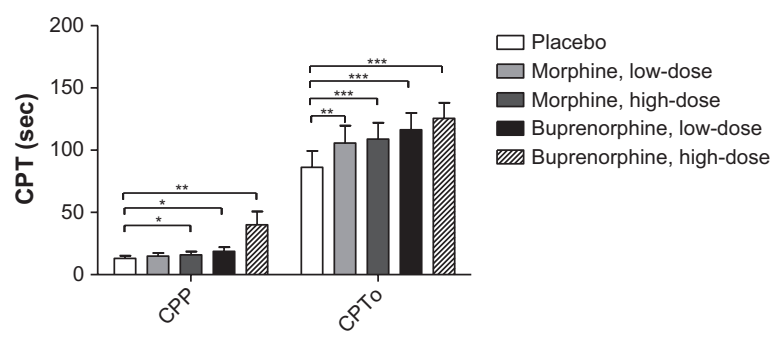

Figure 9 Cold pressor test.

Notes: Cold pressor test with registration of cold pressor pain and cold pressor tolerance. ${ }^{*} P<0.005$, $* * P<0.001$, $* * * P<0.0001$.

Abbreviations: CPP, cold pressor pain; CPT, cold pressor test; CPTo, cold pressor tolerance.

difference in the total number of adverse events reported in low-dose buprenorphine compared to high-dose morphine $(P=0.700)$, both of which had an increased rate of adverse events compared to low-dose morphine $(P<0.001)$. No serious or unexpected adverse events occurred. No significant differences in the number of adverse events between high and low pain-sensitive subjects were seen $(P=0.156)$.

\section{Discussion}

The present study could not demonstrate any clear differences between morphine and buprenorphine in the antihyperalgesia/ analgesia profiles, using an inflammatory pain model with multimodal testing technique in healthy subjects. Furthermore, no differences between high and low pain-sensitive subjects in morphine- and buprenorphine-induced antihyperalgesia and analgesia were observed. High-dose buprenorphine, compared to placebo, was associated with a significant increased action of the descending inhibitory pain control system.

\section{Implications}

The main finding of the present study is clearly at odds with the seminal study by Koppert et al, which used

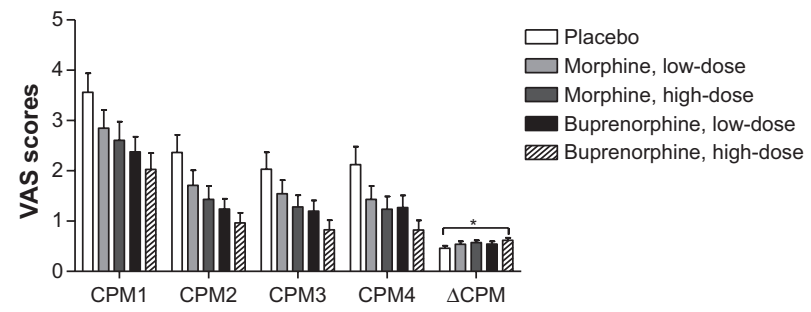

Figure 10 Conditioned pain modulation.

Notes: Visual analog scale scores $(0-10)$ during the test for CPM-efficiency. (Statistics only performed on $\triangle \mathrm{CPM}$ ). $* P<0.005$, $* * P<0.001$, $* * * P<0.0001$.

Abbreviations: $\mathrm{CPMI}$, conditioned pain modulation rating before the cold pressor test; CPM2, conditioned pain modulation rating during the cold pressor test; CPM3, conditioned pain modulation rating 12 seconds after the cold pressor test; CPM4, conditioned pain modulation rating 24 seconds after the cold pressor test; $\triangle \mathrm{CPM}$, conditioned pain modulation efficiency; VAS, visual analog scale. 


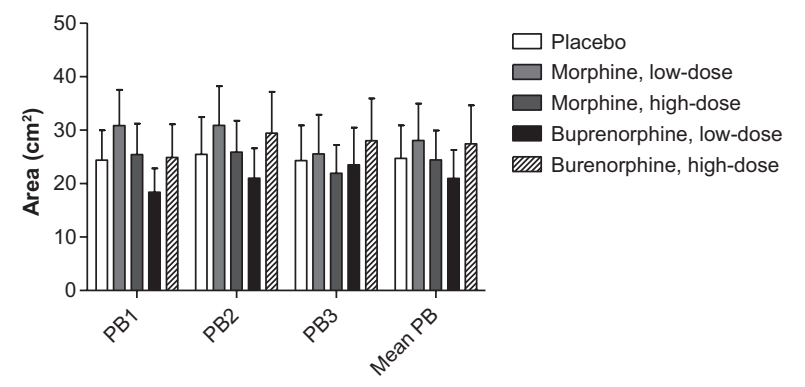

Figure I I Secondary hyperalgesia areas.

Note: Secondary hyperalgesia areas, in the three postburn assessments (PBI-3) and mean postburn values.

Abbreviations: Mean PB, mean of PBI, PB2 and PB3; PBI, I hour postburn; PB2, 2 hours postburn; PB3, 3 hours postburn.

an electrical model with intradermal stimulation and a placebo-controlled administration of buprenorphine $(0.15 \mathrm{mg}$ intravenously/5 minutes). ${ }^{6}$ Their study demonstrated that buprenorphine reduced the hyperalgesic areas by $66 \%$ and the pain ratings by $26 \%$, leading to an antihyperalgesia/analgesia ratio of median 2.6 (interquartile range: $0.8 ; 3.8$ ). The authors concluded, on the basis of recalculation of historical opioid data, that in contrast to pure MOR agonists (eg, fentanyl and alfentanil) with antihyperalgesia/analgesia ratios of $0.6(-0.3 ; 2.2)$ and 0.3 $(-0.3 ; 0.5)$, respectively, it seemed that buprenorphine exerted a more prominent antihyperalgesic than analgesic effect.

A number of differences between the studies are, however, apparent. First, in regard to stimulation methods, the electrical method elicits pain and hyperalgesia by direct axonal stimulation, bypassing the sensory nerve endings. ${ }^{1}$ The heat injury leads to direct activation of nociceptors, initially by a physiological process followed by a pathophysiological inflammatory process. The electrical stimulation method is probably more suitable for examination of central components, ${ }^{1}$ while the heat injury method reflects both peripheral and central components of responses to noxious stimulation. Since high-intensity electrical stimulation is associated with a release of endogenous opioids, ${ }^{37}$ a stimulation-dependent substantial decrease in pain ratings is seen (habituation), in contrast to the heat injury where a stable increase in evoked pain responses is evident $30-45$ minutes after the induction (sensitization). However, both methods seem to induce stable 2HA areas. ${ }^{14,38,39}$ Second, in regard to the stimulation pattern, a constant $2 \mathrm{~Hz}$ paradigm for 3 hours was used in the study by Koppert et al, ${ }^{6}$ while in the present study electrical, mechanical, and heat stimuli of a much shorter duration were used. Third, there are distinct pharmacological differences between the studies. The study by Koppert et al used $25 \%-50 \%$ of the buprenorphine doses used in the present study and administration was bolus-based compared to the 3-hour target-controlled infusion maintaining estimated steady-state concentration (until 1 hour after the heat injury) in the present study. These differences may explain some of the seemingly contradictory results. Interestingly, a recently published study used similar paradigm and methods to Koppert et al to investigate the additive effects of morphine and buprenorphine. ${ }^{1}$ The study used assessments of antihyperalgesia and analgesia as outcome parameters, but the authors did not report the ratios between these outcome parameters. Estimates of data from the accompanying graphics, however, demonstrated an absence of any differential effect between buprenorphine and fentanyl in the antihyperalgesia and analgesia profiles. The estimated ratios between antihyperalgesia and analgesia were $0.75-0.80$ for both drugs.

\section{Antihyperalgesia}

In regard to the heat injury model used in the present study, four studies have been published. ${ }^{40-43}$ In a study with epidural administration of $4 \mathrm{mg}$ morphine $(\mathrm{n}=10)$, a reduction in $2 \mathrm{HA}$ areas of $25 \%$ was seen, compared to placebo. ${ }^{40}$ In another study with local administration of $2 \mathrm{mg}$ morphine subcutaneously $(n=12)$ in the heat injury area, no reduction in $2 \mathrm{HA}$ area or signs of analgesia was seen compared to placebo. ${ }^{41}$ In two studies by Warncke et al $(\mathrm{n}=12)$, antihyperalgesic and analgesic effects were studied following the administration of morphine $(0.21 \mathrm{mg} / \mathrm{kg})$ before and after the heat injury. ${ }^{42,43}$ Only the preinjury administration of morphine had a significant effect, with an $83 \%$ reduction in $2 \mathrm{HA}$ areas compared to placebo and a corresponding $41 \%$ reduction in pinprick pain threshold.

The authors are not able to explain the conflicting results between the present study and the study by Warncke et al. ${ }^{43}$ The sensory assessment methods, the testing paradigm, and drug-dosing scheme are almost identical in the two studies. However, an important aspect is the caliber of monofilament used in the delineation of 2HA areas. The monofilament in the study by Warncke et al had a bending force of $51 \mathrm{mN}(5 \mathrm{~g})$ compared to $890 \pm 50 \mathrm{mN}(91 \pm 5 \mathrm{~g})$ in the present study. Furthermore, in the study by Warncke et al, the tactile pain threshold before drug administration was 2.5 times higher than the bending force of the filament used in the assessment of $2 \mathrm{HA}$, indicating stimulation well below the pain threshold. In most studies using the heat injury, the bending force of the monofilaments quantitating $2 \mathrm{HA}$ areas has been in the range of 20-100 g. ${ }^{44}$ The use of a monofilament with a very small bending force in a drug-free subject could tend to give larger hyperalgesic (ie, allodynia) areas than a rigid monofilament, which is substantiated by the fact that the median values 


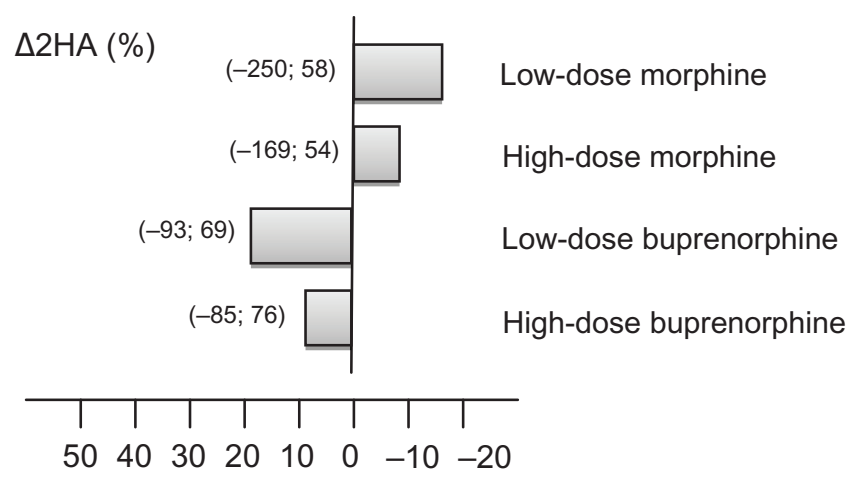

2HA/PHI (median [IQR])

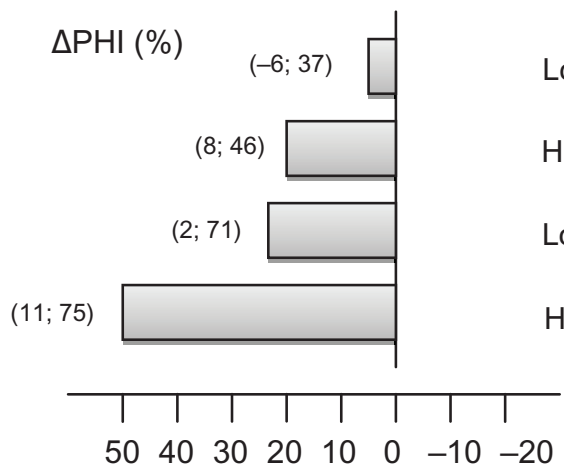

Low-dose morphine $\quad 0.01(-6.2 ; 9.9)$

High-dose morphine $\quad 0.00(-2.4 ; 2.1)$

Low-dose buprenorphine $\quad 0.03(-1.8 ; 2.1)$

High-dose buprenorphine $\quad 0.00(-3.2 ; 1.1)$

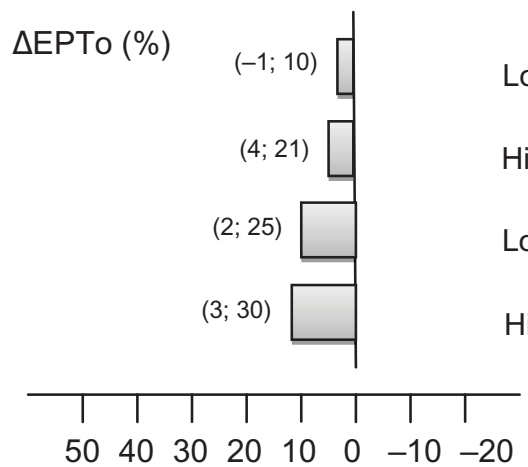

Low-dose morphine $\quad-0.65(-0.9 ;-0.3)$

High-dose morphine $\quad 0.79(0.4 ; 1.1)$

Low-dose buprenorphine $\quad 0.16(0.0 ; 0.4)$

High-dose buprenorphine $0.59(0.2 ; 0.9)$

Figure 12 Anti-hyperalgesia and analgesia.

Notes: Placebo-corrected differences for the active treatments in secondary hyperalgesia areas $(\Delta 2 \mathrm{HA}[\%]$, upper panel), pain-ratings during the heat injury $(\Delta \mathrm{PHI} \%$ ], middle panel), and electrical pain thresholds ( $\Delta \mathrm{EPTo} \%$ ], lower panel). Columns are median (IQR). The anti-hyperalgesia/analgesia ratios $(\Delta 2 \mathrm{HA} / \Delta \mathrm{PHI}$ and $\Delta 2 \mathrm{HA} / \Delta \mathrm{EPTo})$ for the four opioids relative to placebo.

Abbreviations: $\triangle 2 \mathrm{HA}(\%)$, secondary hyperalgesia area relative to placebo; $\Delta \mathrm{PHI}(\%)$, heat injury relative to placebo; $\Delta \mathrm{EPTo}(\%)$, electrical pain tolerance relative to placebo; $2 \mathrm{HA} / \mathrm{PHI}$, ratio (secondary hyperalgesia/heat injury) relative to placebo; $2 \mathrm{HA} / \mathrm{EPTo}$, ratio (secondary hyperalgesia/electrical pain tolerance) relative to placebo; IQR, interquartile range

during the first assessment 30 minutes after induction of the heat injury in the placebo group was $70 \mathrm{~cm}^{2}$ in the Warncke et al study and $23 \mathrm{~cm}^{2}$ in the present study. Correspondingly, stimulation with a light tactile stimulus during opioid exposure could, due to cognitive impairment, lead to a smaller allodynia area than stimulation with a more rigid monofilament.

\section{Analgesia}

The present study corroborates the analgesic effects of morphine observed in a number of studies using heat models (heat injury, heat/capsaicin, brief thermal stimulation). The present study demonstrated a consistent dose-dependent effect in all pain tests with electrical, mechanical, and thermal stimuli. The authors are not aware of any buprenorphine studies using heat models in humans.

The sedative effect of a drug may increase response latency and therefore influence reliability of quantitative sensory testing assessments in studies of analgesic efficacy. ${ }^{45-48}$ Signs of dose-dependent sedation, indicating a potential effect on vigilance and psychomotor performance, were observed for all active treatments in the present study. A drug-mediated increase of pain thresholds are either 
Table 4 Adverse events

\begin{tabular}{|c|c|c|c|c|c|c|c|c|c|c|c|}
\hline Treatment & $\mathbf{N}$ & $\begin{array}{l}\text { Nausea and/ } \\
\text { or vomiting }\end{array}$ & Itch & Sedation & Desaturation & $\begin{array}{l}\text { Urinary } \\
\text { retention }\end{array}$ & $\begin{array}{l}\text { Impairment } \\
\text { in hearing }\end{array}$ & $\begin{array}{l}\text { Visual } \\
\text { disturbance }\end{array}$ & Dizziness & Headache & Total \\
\hline Placebo & 28 & 0 & I & I & 0 & 0 & 0 & 0 & 0 & 0 & 2 \\
\hline $\begin{array}{l}\text { Morphine, } \\
\text { low-dose }\end{array}$ & 27 & 2 & 4 & 3 & I & 0 & I & 0 & 2 & I & 14 \\
\hline $\begin{array}{l}\text { Morphine, } \\
\text { high-dose }\end{array}$ & 28 & 11 & 13 & 11 & 5 & 0 & 2 & I & 6 & I & 50 \\
\hline $\begin{array}{l}\text { Buprenorphine, } \\
\text { low-dose }\end{array}$ & 28 & 14 & II & 15 & 3 & 2 & 2 & I & 6 & 0 & 54 \\
\hline $\begin{array}{l}\text { Buprenorphine, } \\
\text { high-dose }\end{array}$ & 28 & 19 & 18 & 24 & 10 & 2 & I & 1 & 8 & 0 & 83 \\
\hline
\end{tabular}

Notes: Adverse events registered more than once. The numbers refer to the number of subjects, in each treatment arm, who experienced the symptom.

caused by an analgesic effect, an increase in response latency, a modality specific sensory attenuating effect, or a combination of these factors. Since the baseline-corrected sensory detection thresholds (EDT and WDT) did not differ between placebo and active treatments, the dose-dependent increases in pain thresholds and tolerance (EPT, EPTo, and HPT) could mainly be attributed to specific analgesic effects rather than a prolongation of response latencies. It is noteworthy that since CDT decreased (numerical increase in threshold) significantly across active treatments, the increased CPP and CPTo, indicating analgesic efficacy, is probably in part an opioid-mediated decrease in sensitivity to cold stimuli. ${ }^{49,50}$

\section{Equianalgesic doses}

There is controversy in the literature in regard to estimates of equianalgesic doses for buprenorphine and morphine. A number of intravenous studies have reported buprenorphine to be $25-40$ times more potent than morphine. ${ }^{51-53}$ Therefore, a potency ratio of 1:33 was used in the present study, ie, $0.3 \mathrm{mg}$ and $0.6 \mathrm{mg}$ buprenorphine corresponded to $10 \mathrm{mg}$ and $20 \mathrm{mg}$ of morphine, respectively. However, estimates with equianalgesic ratios from 1:60 to 1:100 have also been reported. ${ }^{54,55}$

Estimates of equianalgesic doses depend in part on the pain model (experimental, clinical) and the stimulation type (electrical, mechanical, thermal) used. ${ }^{56}$ Although a number of testing modalities were used in the present study, it is evident by the examination of data pertaining to analgesic effects that the estimated equianalgesic ratio between buprenorphine and morphine was too high. The comparable analgesic effect for high-dose morphine and low-dose buprenorphine indicates that the ratio in the present study should have been at least 1:66 instead of 1:33. Obviously, this may influence the magnitude of the results, which are dose-dependent, but since the primary outcome is a ratio between antihyperalgesic and analgesic effects, it is more likely that the impact on the primary outcome has been limited.

\section{CPM}

An impaired efficiency of the CPM system seems to be an important factor in the transition from acute to chronic pain. ${ }^{12,57}$ Modulation of the CPM system may therefore represent a key to preventive management of chronic pain states. ${ }^{58-60}$ Early studies indicated that low-dose morphine and high-dose naloxone inhibit the action of the descending pain modulation system. ${ }^{61,62}$ However, the only study on opioid-induced modulation of the CPM system in volunteers is a placebo-controlled study $(n=22)$ that used transdermal administration of fentanyl ( $25 \mu \mathrm{g} /$ hour) and buprenorphine $(20 \mu \mathrm{g} /$ hour $)$ with the CPT $\left(3^{\circ} \mathrm{C}, 2\right.$ minutes) as the conditioning stimulus and pressure pain tolerance as the heterotopic test stimulus. ${ }^{12}$ Interestingly, while no analgesic effect in the 72-hour study assessed by pressure pain tolerance was demonstrated, a highly significant potentiating effect on the CPM system was seen during opioid treatment, with no significant differences between fentanyl- and buprenorphine-treated subjects. The present study, however, showed a significant dose-dependent increase in pressure pain tolerance for morphine and buprenorphine (Figure 8), a discrepancy probably explained by differences between the two studies in opioid doses and test period. The present study corroborated the finding of a potentiating effect on CPM efficiency, but only with high-dose buprenorphine (Figure 10). Further studies in volunteers are clearly needed to illuminate the diverging results from clinical studies showing either a decrease or a relative increase in the descending pain modulation system in opioid-treated patients compared to opioid-naïve patients. ${ }^{60,63}$

\section{Pain sensitivity-dependent differences}

Pain hyposensitivity may lead to delayed or incorrect diagnoses, while pain hypersensitivity seems to be associ- 
ated with an increased susceptibility to the development of chronic pain. ${ }^{35,64}$ It has been demonstrated that opioid response patterns are in part determined by opioid- and pain modality-specific analgesic response profiles. ${ }^{65}$ Therefore, it was considered of interest to study the relationship between pain sensitivity and analgesic response across opioids with different MOR and KOP profiles, ie, morphine and buprenorphine. In the present study, subjects were classified in regard to low or high pain sensitivity based on previous PHI. ${ }^{17}$ Significant differences in pain responses between subjects with low or high pain sensitivity were only found in some electrical stimulation tests at baseline and in placebo PHI. The significant differences in pain responses between subjects with low or high pain sensitivity for placebo PHI was anticipated, since this was the discriminating sensitivity test in the forerunning study. The remaining findings were most likely due to type I errors.

\section{Methodology: limitations and advantages}

Since antiemetics (hydrocortisone and ondansetron) were administered to all subjects prophylactically before drug exposure, there is a potential possibility of confounding analgesic effects. ${ }^{20}$ In the heat injury model, glucocorticoids have not demonstrated any analgesic or antihyperalgesic actions, although additive effects with ketorolac (a nonsteroidal antiinflammatory drug) have been proven. Ondansetron does not seem to interact with MOR agonists. ${ }^{66,67}$

Several tests in this study examined the subjects' tolerance level. However, all tolerance tests demonstrated ceiling effects; therefore, these tests might not be well suited for the demonstration of potential pain sensitivity differences - at least not in healthy volunteers.

In the CPM efficiency assessment, four heat stimuli (4 seconds) were delivered to the same skin site in 80 seconds. The successive decrease in pain ratings to the heat stimuli was regarded as a sign of activation of the descending pain modulation system by the conditioning cold pressor stimulus. An alternative explanation could be that the repeated heat stimuli, applied to the same site, caused peripheral habituation and a successive diminution of the pain response. ${ }^{68}$ It is of particular interest that some recent CPM studies have included a 5-15 minute break between the heat prestimulus (with longer duration 7-30 seconds) and the conditioning stimulus. ${ }^{69,70}$ However, temporal stimulation patterns, similar to those presented in several recent studies, were used in the present study. ${ }^{34,63,71}$

A limitation of this study is the multiple comparisons made, which led to an increased probability of type I errors.
Although a significance level of 0.005 was used, it cannot be ruled out that some results are a consequence of mass significance. Nevertheless, it is worth noting that most of the significant results had a $P$-value of 0.001 or less.

A confounding factor is that the subjects retrospectively and correctly identified the placebo treatment in $85 \%$ of the cases. This high percentage was most likely influenced by the fact that they were able to compare all five treatments before identifying the placebo and does not necessarily mean that they were aware of the treatment being placebo on the given day. The prevalence of adverse events was most likely the main cause of correct placebo identification and an active placebo could be considered in future similar studies.

The data validity was enhanced by the use of a limited number of investigators and implementation of standardized methods. Furthermore, all treatment data were corrected for baseline data. This minimizes the bias caused by day-to-day variability. All baseline data were examined for significant differences, which were only observed in three out of 80 baseline comparisons.

The study population could not be considered homogenous in regard to gender and pain sensitivity. The data analyses, however, showed no overall or consistent differences with regard to gender or pain sensitivity. Therefore, combining the groups and investigating them as one large sample was possible.

\section{Conclusion}

In this placebo-controlled crossover study in healthy subjects, an inflammatory heat injury model with multimodal sensory testing technique was used to characterize the antihyperalgesic, analgesic, and descending pain modulation profiles of morphine and buprenorphine. The present study could not demonstrate any differences in the hyperalgesia and analgesia profiles between the opioids. High-dose buprenorphine, but not morphine, was associated with a significant increased effect of the descending inhibitory pain control system. More systematic research in the drug effects on antihyperalgesia, analgesia, and action on the descending pain modulation system is needed.

\section{Acknowledgments}

This work was supported by an unrestricted educational grant from Norpharma A/S (Hørsholm, Denmark). The authors are grateful to Sara Grünfeld, Per Rotbøll-Nielsen, and Hanne M. Hansen for their valuable contribution in surveillance of the study volunteers. The authors appreciate the scientific discussions with Dorthe Tvinnemose. The authors highly 
appreciate the opportunity to use the facilities at the Phase One Trial Unit (ZELO) at Bispebjerg Hospital (Copenhagen, Denmark) and thank Torben Balchen and Jesper Sonne for their help and hospitality. The help of Philip Hojrizi with the study drugs is highly appreciated.

\section{Disclosure}

The authors report no conflicts of interest in this work.

\section{References}

1. Troster A, Ihmsen H, Singler B, Filitz J, Koppert W. Interaction of fentanyl and buprenorphine in an experimental model of pain and central sensitization in human volunteers. Clin J Pain. 2012;28(8): 705-711.

2. Angst MS, Clark JD. Opioid-induced hyperalgesia: a qualitative systematic review. Anesthesiology. 2006;104(3):570-587.

3. Koppert W. Opioid-induced hyperalgesia - pathophysiology and clinical relevance. Acute Pain. 2007;9:21-34.

4. Caroll IR, Angst MS, Clark JD. Management of perioperative pain in patients chronically consuming opioids. Reg Anesth Pain Med. 2004; 29(6):576-591.

5. Andresen T, Upton RN, Foster DJ, Christrup LL, Arendt-Nielsen L, Drewes AM. Pharmacokinetic/pharmacodynamic relationships of transdermal buprenorphine and fentanyl in experimental human pain models. Basic Clin Pharmacol Toxicol. 2011;108(4):274-284.

6. Koppert W, Ihmsen H, Korber N, et al. Different profiles of buprenorphine-induced analgesia and antihyperalgesia in a human pain model. Pain. 2005;118(1-2):15-22.

7. Angst MS, Phillips NG, Drover DR, et al. Pain sensitivity and opioid analgesia: a pharmacogenomic twin study. Pain. 2012;153(7): 1397-1409.

8. Abrishami A, Chan J, Chung F, Wong J. Preoperative pain sensitivity and its correlation with postoperative pain and analgesic consumption: a qualitative systematic review. Anesthesiology. 2011;114(2):445-457.

9. Werner MU, Mjobo HN, Nielsen PR, Rudin A. Prediction of postoperative pain: a systematic review of predictive experimental pain studies. Anesthesiology. 2010;112(6):1494-1502.

10. Clauw DJ, Williams D, Lauerman W, et al. Pain sensitivity as a correlate of clinical status in individuals with chronic low back pain. Spine (Phila Pa 1976). 1999;24(19):2035-2041.

11. King CD, Wong F, Currie T, Mauderli AP, Fillingim RB, Riley JL 3rd. Deficiency in endogenous modulation of prolonged heat pain in patients with irritable bowel syndrome and temporomandibular disorder. Pain. 2009;143(3):172-178.

12. Arendt-Nielsen L, Andresen T, Malver LP, Oksche A, Mansikka H, Drewes AM. A double-blind, placebo-controlled study on the effect of buprenorphine and fentanyl on descending pain modulation: a human experimental study. Clin J Pain. 2011;28(7):623-627.

13. Yarnitsky D, Arendt-Nielsen L, Bouhassira D, et al. Recommendations on terminology and practice of psychophysical DNIC testing. Eur $J$ Pain. 2010;14(4):339.

14. Naert AL, Kehlet H, Kupers R. Characterization of a novel model of tonic heat pain stimulation in healthy volunteers. Pain. 2008;138(1): 163-171.

15. Pedersen JL, Kehlet H. Hyperalgesia in a human model of acute inflammatory pain: a methodological study. Pain. 1998;74(2-3): $139-151$.

16. Werner MU, Duun P, Kehlet H. Prediction of postoperative pain by preoperative nociceptive responses to heat stimulation. Anesthesiology. 2004;100(1):115-119.

17. Ravn P, Frederiksen R, Skovsen AP, Christrup LL, Werner MU. Prediction of pain sensitivity in healthy volunteers. J Pain Res. 2012;5: 313-326.
18. Yassen A, Olofsen E, Romberg R, Sarton E, Danhof M, Dahan A. Mechanism-based pharmacokinetic-pharmacodynamic modeling of the antinociceptive effect of buprenorphine in healthy volunteers. Anesthesiology. 2006;104(6):1232-1242.

19. Mazoit JX, Butscher K, Samii K. Morphine in postoperative patients: pharmacokinetics and pharmacodynamics of metabolites. Anesth Analg. 2007;105(1):70-78.

20. Gan TJ, Meyer TA, Apfel CC, et al. Society for Ambulatory Anesthesia guidelines for the management of postoperative nausea and vomiting. Anesth Analg. 2007;105(6):1615-1628.

21. Bjelland I, Dahl AA, Haug TT, Neckelmann D. The validity of the Hospital Anxiety and Depression Scale. An updated literature review. J Psychosom Res. 2002;52(2):69-77.

22. Sullivan MJL, Bishop SR, Kivik J. The pain catastrophizing scale: development and validation. Psychol Assess. 1995;7(4):524-532.

23. Borly L, Anderson IB, Bardram L, et al. Preoperative prediction model of outcome after cholecystectomy for symptomatic gallstones. Scand $J$ Gastroenterol. 1999;34(11):1144-1152.

24. Jorgensen T, Teglbjerg JS, Wille-Jorgensen P, Bille T, Thorvaldsen P. Persisting pain after cholecystectomy. A prospective investigation. Scand J Gastroenterol. 1991;26(1):124-128.

25. Zigmond AS, Snaith RP. The hospital anxiety and depression scale. Acta Psychiatr Scand. 1983;67(6):361-370.

26. Bisgaard T, Klarskov B, Rosenberg J, Kehlet H. Characteristics and prediction of early pain after laparoscopic cholecystectomy. Pain. 2001; 90(3):261-269.

27. Gill DM, Reddon JR, Stefanyk WO, Hans HS. Finger tapping: effects of trials and sessions. Percept Mot Skills. 1986;62(2):675-678.

28. Zacny JP, Gutierrez S. Subjective, psychomotor, and physiological effects profile of hydrocodone/acetaminophen and oxycodone/acetaminophen combination products. Pain Med. 2008;9(4):433-443.

29. Stener-Victorin E, Kowalski J, Lundeberg T. A new highly reliable instrument for the assessment of pre- and postoperative gynecological pain. Anesth Analg. 2002;95(1):151-157.

30. Moller KA, Johansson B, Berge OG. Assessing mechanical allodynia in the rat paw with a new electronic algometer. $J$ Neurosci Methods. 1998;84(1-2):41-47.

31. Werner MU, Rotboll-Nielsen P, Ellehuus-Hilmersson C. Humidity affects the performance of von Frey monofilaments. Acta Anaesthesiol Scand. 2011;55(5):577-582.

32. Pud D, Granovsky Y, Yarnitsky D. The methodology of experimentally induced diffuse noxious inhibitory control (DNIC)-like effect in humans. Pain. 2009;144(1-2):16-19.

33. Yarnitsky D, Crispel Y, Eisenberg E, et al. Prediction of chronic postoperative pain: pre-operative DNIC testing identifies patients at risk. Pain. 2008;138(1):22-28.

34. Eisenberg E, Midbari A, Haddad M, Pud D. Predicting the analgesic effect to oxycodone by "static" and "dynamic" quantitative sensory testing in healthy subjects. Pain. 2010;151(1):104-109.

35. Nielsen CS, Stubhaug A, Price DD, Vassend O, Czajkowski N, Harris JR. Individual differences in pain sensitivity: genetic and environmental contributions. Pain. 2008;136(1-2):21-29.

36. Verbraecken J, Van de Heyning P, De Backer W, Van Gaal L. Body surface area in normal-weight, overweight, and obese adults. A comparison study. Metabolism. 2006;55(4):515-524.

37. Koppert W, Angst M, Alsheimer M, et al. Naloxone provokes similar pain facilitation as observed after short-term infusion of remifentanil in humans. Pain. 2003;106(1-2):91-99.

38. Pedersen JL, Kehlet H. Secondary hyperalgesia to heat stimuli after burn injury in man. Pain. 1998;76(3):377-384.

39. Weidner C, Schmelz M, Schmidt R, Hansson B, Handwerker HO, Torebjork HE. Functional attributes discriminating mechano-insensitive and mechano-responsive C nociceptors in human skin. J Neurosci. 1999; 19(22):10184-10190.

40. Brennum J, Arendt-Nielsen L, Horn A, Secher NH, Jensen TS. Quantitative sensory examination during epidural anaesthesia and analgesia in man: effects of morphine. Pain. 1993;52(1):75-83. 
41. Lilleso J, Hammer NA, Pedersen JL, Kehlet H. Effect of peripheral morphine in a human model of acute inflammatory pain. Br JAnaesth. 2000;85(2):228-232.

42. Warncke T, Stubhaug A, Jorum E. Ketamine, an NMDA receptor antagonist, suppresses spatial and temporal properties of burn-induced secondary hyperalgesia in man: a double-blind, cross-over comparison with morphine and placebo. Pain. 1997;72(1-2):99-106.

43. Warncke T, Stubhaug A, Jorum E. Preinjury treatment with morphine or ketamine inhibits the development of experimentally induced secondary hyperalgesia in man. Pain. 2000;86(3):293-303.

44. Werner MU, Pedersen KL, Rowbotham MC, Dahl JB. Can healthy volunteers be phenotyped using cutaneous sensitization models? Forthcoming 2012.

45. Klauenberg S, Maier C, Assion HJ, et al. Depression and changed pain perception: hints for a central disinhibition mechanism. Pain. 2008; 140(2):332-343.

46. Wang H, Fischer C, Chen G, Weinsheimer N, Gantz S, Schiltenwolf M. Does long-term opioid therapy reduce pain sensitivity of patients with chronic low back pain? Evidence from quantitative sensory testing. Pain Physician. 2012;15(Suppl 3):ES135-ES143.

47. Werner MU, Perkins FM, Holte K, Pedersen JL, Kehlet H. Effects of gabapentin in acute inflammatory pain in humans. Reg Anesth Pain Med. 2001;26(4):322-328.

48. Brennum J, Dahl JB, Moiniche S, Arendt-Nielsen L. Quantitative sensory examination of epidural anaesthesia and analgesia in man: effects of pre- and post-traumatic morphine on hyperalgesia. Pain. 1994;59(2): 261-271.

49. Park R, Wallace MS, Schulteis G. Relative sensitivity to alfentanil and reliability of current perception threshold vs von Frey tactile stimulation and thermal sensory testing. J Peripher Nerv Syst. 2001;6(4): $232-240$.

50. Leung A, Wallace MS, Ridgeway B, Yaksh T. Concentration-effect relationship of intravenous alfentanil and ketamine on peripheral neurosensory thresholds, allodynia and hyperalgesia of neuropathic pain. Pain. 2001;91(1-2):177-187.

51. Cowan A. Buprenorphine: new pharmacological aspects. Int J Clin Pract Suppl. 2003;133:3-8.

52. Kuhlman JJ Jr, Lalani S, Magluilo J Jr, Levine B, Darwin WD. Human pharmacokinetics of intravenous, sublingual, and buccal buprenorphine. J Anal Toxicol. 1996;20(6):369-378.

53. Belcheva MM, Barg J, McHale RJ, et al. Differential down- and up-regulation of rat brain opioid receptor types and subtypes by buprenorphine. Mol Pharmacol. 1993;44(1):173-179.

54. Twycross RG. Opioid analgesics in cancer pain: current practice and controversies. Cancer Surv. 1988;7(1):29-53.

55. Sittl R. Transdermal buprenorphine in cancer pain and palliative care. Palliat Med. 2006;20(Suppl 1):s25-s30.

56. Andresen T, Staahl C, Oksche A, Mansikka H, Arendt-Nielsen L, Drewes AM. Effect of transdermal opioids in experimentally induced superficial, deep and hyperalgesic pain. Br J Pharmacol. 2011;164(3): 934-945.
57. Yarnitsky D. Conditioned pain modulation (the diffuse noxious inhibitory control-like effect): its relevance for acute and chronic pain states. Curr Opin Anaesthesiol. 2010;23(5):611-615.

58. Julien N, Goffaux P, Arsenault P, Marchand S. Widespread pain in fibromyalgia is related to a deficit of endogenous pain inhibition. Pain. 2005;114(1-2):295-302.

59. Johannesson U, de Boussard CN, Brodda Jansen G, Bohm-Starke N. Evidence of diffuse noxious inhibitory controls (DNIC) elicited by cold noxious stimulation in patients with provoked vestibulodynia. Pain. 2007;130(1-2):31-39.

60. Olesen SS, Brock C, Krarup AL, et al. Descending inhibitory pain modulation is impaired in patients with chronic pancreatitis. Clin Gastroenterol Hepatol. 2010;8(8):724-730.

61. Le Bars D, Willer JC, De Broucker T. Morphine blocks descending pain inhibitory controls in humans. Pain. 1992;48(1):13-20.

62. Willer JC, Le Bars D, De Broucker T. Diffuse noxious inhibitory controls in man: involvement of an opioidergic link. Eur J Pharmacol. 1990;182(2):347-355.

63. Ram KC, Eisenberg E, Haddad M, Pud D. Oral opioid use alters DNIC but not cold pain perception in patients with chronic pain - new perspective of opioid-induced hyperalgesia. Pain. 2008;139(2):431-438.

64. Nielsen CS, Staud R, Price DD. Individual differences in pain sensitivity: measurement, causation, and consequences. J Pain. 2009;10(3):231-237.

65. Kindler LL, Valencia C, Fillingim RB, George SZ. Sex differences in experimental and clinical pain sensitivity for patients with shoulder pain. Eur J Pain. 2011;15(2):118-123.

66. Petersen-Felix S, Arendt-Nielsen L, Bak P, et al. Ondansetron does not inhibit the analgesic effect of alfentanil. Br J Anaesth. 1994;73(3): 326-330.

67. Stubhaug A, Romundstad L, Kaasa T, Breivik H. Methylprednisolone and ketorolac rapidly reduce hyperalgesia around a skin burn injury and increase pressure pain thresholds. Acta Anaesthesiol Scand. 2007;51(9): $1138-1146$.

68. Greffrath W, Baumgartner U, Treede RD. Peripheral and central components of habituation of heat pain perception and evoked potentials in humans. Pain. 2007;132(3):301-311.

69. Granot M, Weissman-Fogel I, Crispel Y, et al. Determinants of endogenous analgesia magnitude in a diffuse noxious inhibitory control (DNIC) paradigm: do conditioning stimulus painfulness, gender and personality variables matter? Pain. 2008;136(1-2):142-149.

70. Yarnitsky D, Granot M, Nahman-Averbuch H, Khamaisi M, Granovsky Y. Conditioned pain modulation predicts duloxetine efficacy in painful diabetic neuropathy. Pain. 2012;153(6):1193-1198.

71. Treister R, Eisenberg E, Gershon E, Haddad M, Pud D. Factors affecting - and relationships between - different modes of endogenous pain modulation in healthy volunteers. Eur J Pain. 2010;14(6): 608-614.
Journal of Pain Research

\section{Publish your work in this journal}

The Journal of Pain Research is an international, peer-reviewed, open access, online journal that welcomes laboratory and clinical findings in the fields of pain research and the prevention and management of pain. Original research, reviews, symposium reports, hypothesis formation and commentaries are all considered for publication.

\section{Dovepress}

The manuscript management system is completely online and includes a very quick and fair peer-review system, which is all easy to use. Visit http://www.dovepress.com/testimonials.php to read real quotes from published authors. 